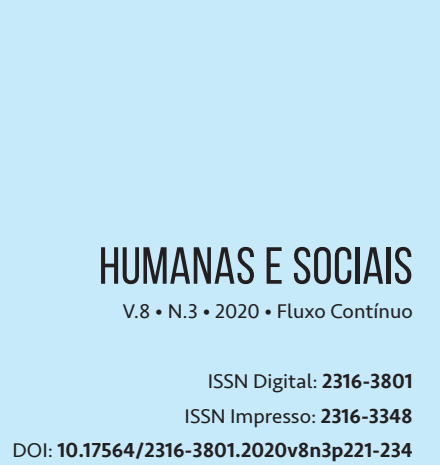

\section{VIOLÊNCIA DE GÊNERO E DIREITO DAS MULHERES NO BRASIL}

GENDER VIOLENCE AND WOMEN'S RIGHTS IN BRAZIL

VIOLENCIA DE GÉNERO Y DERECHOS DE LAS MUJERES EN BRASLL

Kellen Cristina Varisco Lazzari ${ }^{1}$ Paula Pinhal de Carlos ${ }^{2}$

Aline Accorssi ${ }^{3}$

\section{RESUMO}

Este artigo trata do reconhecimento dos direitos das mulheres brasileiras no que se refere à violência de gênero. Para tanto, apresenta os direitos previstos na legislação e as políticas públicas implementadas no país sobre o tema. Inicia contextualizando o debate feminista sobre os crimes cometidos sob o argumento da legítima defesa da honra, a criação das Delegacias Especiais de Atendimento à Mulher e a criação da Lei dos Juizados Especiais Criminais em 1990, que caracterizava os crimes de lesão corporal e ameaça como crimes de menor potencial ofensivo. Por fim, discute sobre a criação da Lei Maria da Penha, que inaugurou um novo momento da legislação brasileira no enfrentamento à violência de gênero.

\section{PALAVRAS-CHAVE}

Violência de Gênero. Direitos das Mulheres. Lei Maria da Penha. 


\section{ABSTRACT}

This paper deals with the recognition of Brazilian women rights in regard to gender violence. In order to do it, it presents the rights related to this subject that are set out in the law and the public policies implemented in the country. First, we contextualize the feminist debate over crimes committed on the grounds of honor self-defense, the creation of Special Units for Women as well as the creation of the Law of Special Criminal Courts in 1990, which characterizes the crimes of bodily injury and threat as lower offensive potential crimes. Finally, we discuss the creation of Maria da Penha Law, which was the beginning of a new moment of Brazilian legislation in addressing gender-based violence.

\section{KEYWORDS}

Gender violence. Women rights. Maria da Penha Law.

Este documento trata sobre el reconocimiento de los derechos de las mujeres brasileñas con respecto a la violencia de género. Para ello, presenta los derechos relacionados con este tema que se establecen en la ley y las políticas públicas implementadas en el país. Primero, contextualizamos el debate feminista sobre los crímenes cometidos con base en la legítima defensa del honor, la creación de Unidades Especiales para la Mujer, así como la creación de la Ley de Tribunales Penales Especiales en 1990, que caracteriza los crímenes de lesiones corporales y amenazas. como delitos potenciales ofensivos más bajos. Finalmente, discutimos la creación de la Ley Maria da Penha, que fue el comienzo de un nuevo momento de la legislación brasileña para abordar la violencia de género. 


\section{DIREITOS DAS MULHERES BRASILEIRAS NOS ANOS 1980}

É apenas com a aproximação do final do período ditatorial, iniciado em 1964, que se intensifica e é visibilizada a luta das mulheres brasileiras no combate à violência. Com o intuito de buscar a cidadania (PINTO, 2003), a igualdade de direitos, de tratamento, a diminuição da dominação masculina e a submissão das mulheres, o feminismo (no Brasil), desde o início dos anos de 1980, articulou-se em movimentos para acabar com a discriminação e a violência gerada contra elas. Com a busca por parcerias, pressionando o Estado, a fim de tratar desse problema social, passou a exigir serviços e ações que buscassem enfrentar o problema da violência contra as mulheres.

Nesse período, o Brasil passava pela repercussão de um dos crimes passionais mais conhecidos do país: o caso “Doca Street”. Raul Fernando do Amaral Street, o Doca, matou sua namorada, Ângela Diniz, após uma violenta discussão entre o casal, em dezembro de 1976. Doca teve dois julgamentos: o primeiro ocorreu em 1979, onde se beneficiou com a tese do excesso culposo no estado de legítima defesa da honra e o juiz fixou a pena de dois anos de detenção ao réu, concedendo-lhe o direito ao sursis (suspensão da execução da pena privativa de liberdade imposta sob determinadas condições), teve como advogado de defesa o conceituado criminalista brasileiro Evandro Lins e Silva, que fez de tudo para desqualificar a vítima e se esforçou ao máximo para demonstrar que seu cliente era um homem honesto e com bons antecedentes.

O Movimento Feminista, então, se reuniu e foi às ruas, com cartazes que diziam "Quem ama não mata”. Em 1981, foi a julgamento novamente e foi condenado a 15 anos de reclusão. Cumpriu três anos em regime fechado, dois anos no semiaberto e o restante em condicional (medida que visa antecipar a saída do condenado da prisão, porém sua liberdade ficara condicionada ao cumprimento de determinadas obrigações que possibilitariam sua reabilitação ao ambiente social).

As primeiras políticas públicas brasileiras com recorte de gênero, foram implementadas na década de 1980. Houve a criação, no Estado de São Paulo, do primeiro Conselho Estadual da Condição Feminina (em 1983) e a primeira Delegacia de Polícia de Defesa da Mulher (em 1985). Após a criação do Conselho Nacional dos Direitos das Mulheres, pelo Ministério da Justiça (em 1985), essas instituições se disseminaram por todo o Brasil (FARAH, 2004).

A violência no âmbito familiar foi coibida desde a Constituição Federal (CF) de 1988, nos termos do $\S 8^{\circ}$, do artigo 226, que dispõe: “O Estado assegurará a assistência à família na pessoa de cada um dos que a integram, criando mecanismos para coibir a violência no âmbito de suas relações”. "O movimento feminista 4 foi um dos grandes responsáveis para que os crimes cometidos contra as mulheres

\footnotetext{
4 A história do feminismo pode ser dividida em três “ondas". A primeira teria ocorrido nos Estados Unidos e no Reino Unido, entre o final do século XIX e o início do século XX. Destaca-se, aí, a luta pelo direito ao voto. No Brasil, a primeira onda também ocorreu pelo direito ao voto, conquistado em 1932. A segunda onda do feminismo tem a forte influência das ideias da escritora francesa Simone de Beauvoir, autora do livro 0 Segundo Sexo. Teve início na década de 60, com duração até o final da década de 1980, e como foco um movimento libertário, na busca de uma nova forma de relacionamento entre homens e mulheres; chamou atenção para a dominação do homem sobre a mulher. No Brasil, a conjuntura da segunda onda corresponde ao período da Ditadura Militar (1964-1989), o que levou as feministas a se rebelarem contra o regime, também contra a opressão de gênero. A
} 
passassem a ser considerados como violação aos direitos humanos” (CAMPOS, 2000, p. 30).

A Conferência Mundial dos Direitos Humanos, realizada em Viena, Áustria, em 1993, no seu Artigo 18, reconheceu que "os Direitos Humanos das mulheres e das meninas são inalienáveis e constituem parte integrante e indivisível dos Direitos Humanos Universais” e que a violência de gênero é incompatível com a dignidade e o valor da pessoa humana.

A Convenção Interamericana para Prevenir, Punir e Erradicar a Violência Contra a Mulher - Convenção de Belém do Pará, Organização dos Estados Americanos (OEA), de julho de 1994, ratificada pelo Brasil em 27 de novembro de 1995, define a violência contra a mulher como "qualquer ato ou conduta baseada no gênero, que cause morte, dano ou sofrimento físico ou psicológico à mulher, tanto na esfera pública quanto na esfera privada".

Portanto, a violência contra a mulher não pode ser separada da categoria de gênero, pois deve ser entendida como reflexo de desigualdade social, econômica e política, reforçadas por uma cultura e ideologias sexistas ${ }^{5}$, racistas $^{6}$, classistas $^{7}$, de dominação e exclusão. Tais relações estão mediadas por uma ordem patriarcal na sociedade brasileira, a qual atribui, aos homens, o direito a dominar e controlar suas mulheres, podendo, em alguns casos, chegar à violência física.

Essa dominação masculina obtém na sociedade as condições para que haja a sua disseminação, visto que mulheres ainda se encontram como dependentes e submissas aos homens, tanto no que se refere a diversos planos, como econômico, social e cultural. Para Pierre Bourdieu (2003), a dominação masculina não se encerra na dependência e submissão das mulheres; ela vai mais fundo: são concepções, significações criadas pela sociedade, que estão incutidas em homens e mulheres de maneira invisível, mascarando o poder do homem, que existe nas relações, tornando essas concepções, do que é ser homem e mulher, como naturais.

terceira onda do feminismo começou no início da década de 1990, como uma resposta às supostas falhas da segunda onda, e também como uma retaliação a iniciativas e movimentos criados pela segunda onda. Buscaram-se medidas de proteção às mulheres e maior participação delas na política, e a luta contra a violência (GARCIA, 2011; PINTO, 2010).

5 Sexismo: atitude, discurso ou comportamento, que se baseia no preconceito e na discriminação sexual: a exaltação exagerada do masculino ou do feminino é uma forma de sexismo, informação disponível em: http://www.dicio.com.br/sexismo/. Acesso em: 18 jun. 2014. Em relação a gênero, o sexismo como preconceito com a mulher pode ser dividido em: "Sexismo hostil: evidencia crenças e práticas típicas de pessoas que consideram as mulheres inferiores aos homens, refletindo antipatia e intolerância em relação ao seu papel como figura de poder e decisão. Sexismo benévolo: refere-se a uma atitude positiva, aparentemente não preconceituosa, em relação à mulher, evidenciando o sentido paternalista que a descreve como pessoa frágil, que necessita atenção, mas que, também, pode complementar o homem" (FORMIGA et al., 2002, p.84).

6 Racista é quem tem um comportamento, uma ação resultante da aversão, em muitos casos, de ódio, em relação a pessoas que possuem sinais alusivos à raça negra, tais como: cor da pele, tipo de cabelo etc. (GUIMARÃES, 1999). "Na verdade, quem é racista, vive o paradoxal desejo de exterminar determinado grupo, ao mesmo tempo em que necessita da sua existência para continuar assumindo um lugar superior" (CUNHA, 2008, p. 346-347).

7 “O adjetivo 'classista' é atribuído àqueles movimentos que adotam a perspectiva de classe do lugar que sua base social ocupa nas estruturas sociais, ou seja, não se aplica a outros movimentos que não adotam essa perspectiva, embora apresentem elevado senso crítico (incluindo retórica classista, mas não perspectiva) em relação ao status quo e suas demandas e/ou objetivos possam ser identificados como de classe" (PINHEIRO, 2010, p. 149). 0 conceito de classe é referenciado na perspectiva marxiana, definindo a localização dos setores sociais quanto às relações de produção (MARX, 1983). 


\section{DA LEI DOS JUIZADOS ESPECIAIS CRIMINAIS À LEI MARIA DA PENHA}

Após a CF de 1988, os casos de violência de gênero eram tratados segundo a égide da Lei $n^{\circ}$ 9.099/1995, Lei dos Juizados Especiais Cíveis e Criminais. Essa lei criou mecanismos de solução de conflitos, destinados aos crimes de menor potencial ofensivo, aqueles cujas condutas tipificadas tenham pena máxima não superior a dois anos.

Os Juizados especiais Criminais (JECRIMs) foram severamente criticados pelas feministas e demais estudiosos e profissionais que trabalham com a violência doméstica. Os formuladores dos JECRIMs não contavam com a grande demanda dos casos de violência doméstica, pensaram em uma política criminal inacabada, sem uma perspectiva de gênero. (PESTANA, 2010, p. 75).

Em 2003, foi criada a Secretaria de Políticas para as Mulheres (SPM) no âmbito do governo federal e tivemos o início da Política Nacional de Enfrentamento à Violência contra as Mulheres, além de uma efetiva rede de atendimento às mulheres em situação de violência, pois foram propiciados recursos para a criação de serviços e para a realização de políticas públicas integradas de enfrentamento à violência contra as mulheres.

Além dos avanços acima citados, os movimentos feministas brasileiros obtiveram inúmeras conquistas, como a regulamentação que trata da notificação compulsória de violência contra a mulher no atendimento prestado em quaisquer serviços de saúde, sejam públicos ou privados, por meio da Portaria n².406/2004, do Ministério da Saúde; as Delegacias para Mulheres; a Lei Maria da Penha (LMP); e diversas políticas públicas no combate à violação aos direitos das mulheres. Essas políticas públicas atuam de forma complementar às normas jurídicas, junto com as leis, a fim de tornar efetivos os direitos das mulheres previstos no ordenamento jurídico.

As mulheres, há décadas, lutam contra a exclusão social, para mudar o estigma que sempre lhes fixou o papel, único e exclusivo, de reprodutoras, donas-de-casa e o caráter de fragilidade. Um exemplo vivo e brasileiro de luta contra a exclusão e a violência de gênero é o da farmacêutica bioquímica cearense, Maria da Penha Maia Fernandes, que ficou conhecida não apenas no Brasil, mas também fora dele, pois, em 1998, com o intuito de lutar por seus direitos, também o de todas as mulheres brasileiras, em parceria com o Comitê Latino-americano e do Caribe para a Defesa dos Direitos da Mulher (CLADEM), o Centro pela Justiça e o Direito Internacional (CEJIL), denunciou o Brasil na Comissão Interamericana de Direitos Humanos da OEA, por causa da sua tolerância e omissão estatal, na qual eram tratados pela justiça brasileira os casos de violência contra a mulher.

Maria da Penha Maia Fernandes virou símbolo contra a violência doméstica. Em 1983, o seu marido na época, professor universitário Marco Antônio Herredia, tentou matá-la duas vezes. Na primeira, deu-lhe um tiro que a deixou paraplégica e, após se recuperar, a manteve em cárcere privado. Maria sofreu, ainda, outras agressões, e uma nova tentativa de assassinato (por eletrocussão).

Na ocasião, ela tinha 38 anos e três filhas. A investigação começou em junho do mesmo ano, mas a denúncia só foi apresentada ao Ministério Público Estadual em setembro de 1984. Somente 
oito anos depois, Herredia foi condenado a oito anos de prisão, mas usou de recursos jurídicos para protelar o cumprimento da pena ${ }^{8}$. Em 28 de outubro de 2002, foi preso e cumpriu dois anos de prisão em regime fechado? .

Foi então que o caso chegou à Comissão Interamericana dos Direitos Humanos da OEA, que acatou, pela primeira vez, a denúncia de um crime de violência doméstica. Condenando, assim, o Brasil, que foi obrigado a cumprir algumas recomendações, dentre as quais a de mudar a legislação brasileira, de maneira a permitir, nas relações de gênero, a prevenção e a proteção da mulher em situação de violência doméstica, bem como a punição do agressor.

Dessa forma, o governo federal, por meio da SPM de Políticas Públicas para Mulheres, em parceria com cinco organizações não governamentais, atendendo aos importantes tratados internacionais, assinados e ratificados pelo Brasil, criou um projeto de lei que, após aprovado por unanimidade na Câmara e no Senado Federal, foi transformado, em agosto de 2006, na Lei 11.340. Essa lei é conhecida pelo nome da mulher que se fez notar pela luta por seus direitos e de todas as mulheres do país: Lei Maria da Penha.

A Lei 11.340/2006 prevê mecanismos para coibir e prevenir a violência doméstica e familiar contra a mulher, medidas protetivas, ainda dispõe sobre a criação dos juizados de violência doméstica e familiar, o que tem sido viabilizado pelas ações de efetivação da chamada LMP:

Art. 10 Esta Lei cria mecanismos para coibir e prevenir a violência doméstica e familiar contra a mulher, nos termos do § 80 do art. 226 da Constituição Federal, da Convenção sobre a Eliminação de Todas as Formas de Violência contra a Mulher, da Convenção Interamericana para Prevenir, Punir e Erradicar a Violência contra a Mulher e de outros tratados internacionais ratificados pela República Federativa do Brasil; dispõe sobre a criação dos Juizados de Violência Doméstica e Familiar contra a Mulher; e estabelece medidas de assistência e proteção às mulheres em situação de violência doméstica e familiar. Art. 20 Toda mulher, independentemente de classe, raça, etnia, orientação sexual, renda, cultura, nível educacional, idade e religião, goza dos direitos fundamentais inerentes à pessoa humana, sendo-lhe asseguradas as oportunidades e facilidades para viver sem violência, preservar sua saúde física e mental e seu aperfeiçoamento moral, intelectual e social.

A LMP criou muitas medidas para proteger a mulher que sofre violência doméstica e familiar, entre elas, o afastamento do agressor do lar ou do local onde convive com a agredida; proibição de frequentar determinados lugares, como a casa ou o trabalho da agredida; proibição de se aproximar ou manter contato com a agredida, seus parentes e com as testemunhas da agressão; encaminhamento da agredida e de seus dependentes a programas de proteção e atendimento da mulher em situação de violência doméstica e familiar; garantia da volta da agredida e de seus filhos ao lar abandonado, em razão da agressão sofrida.

Logo após ser determinado o afastamento do agressor; direito da vítima de sair do lar com seus filhos nos casos de perigo, ou ali permanecer, com o afastamento ou prisão do agressor; na LMP,

8 Disponível em: http://www.mpce.mp.br/nespeciais/promulher/mariadapenha.asp. Acesso em: 19 mar. 2014.

9 Disponível em: http://www2.uol.com.br/vyaestelar/amorpassional_maria_da_penha.htm. Acesso em: 19 mar. 2014.

Interfaces Científicas • Aracaju • V.8 • N.3 • p. 221-234 • 2020 • Fluxo Contínuo 
também há medidas protetivas ao patrimônio da mulher (vítima); o juiz, ao aplicar a LMP, pode, também, determinar que o agressor participe de programas de recuperação e educação, de modo que as agressões não se repitam ${ }^{10}$.

Abaixo, construímos um quadro com as diferenças entre a Lei 9.099/1995 e a Lei 11.340/2006, em vigor atualmente e aplicável aos crimes de violência doméstica e familiar contra a mulher.

Quadro 1 - diferenças entre a Lei 9.099/1995 e a Lei 11.340/2006

\begin{tabular}{|c|c|}
\hline LEI no 9.099/1995 & LEI No 11.340/2006 \\
\hline Não estabelecia as formas dessa violência. & $\begin{array}{l}\text { Tipifica, define violência doméstica e familiar con- } \\
\text { tra a mulher, e estabelece as formas de violência } \\
\text { doméstica contra as mulheres, como sendo física, } \\
\text { psicológica, sexual, patrimonial, e moral. }\end{array}$ \\
\hline $\begin{array}{l}\text { Permitia a aplicação de penas pecuniárias, como } \\
\text { as de pagamento de cestas básicas e multa. }\end{array}$ & Proíbe a aplicação dessas penas. \\
\hline $\begin{array}{l}\text { Os Juizados Especiais Criminais tratavam somen- } \\
\text { te do crime. Para resolver questões de família, } \\
\text { como separação, pensão, e guarda dos filhos, a } \\
\text { mulher, vítima de violência, tinha que ingressar } \\
\text { com outro processo, na vara da família. }\end{array}$ & $\begin{array}{l}\text { Serão criados Juizados Especiais de violência do- } \\
\text { méstica e familiar contra a mulher com competên- } \\
\text { cia civil e criminal, para abranger todas as questões. }\end{array}$ \\
\hline $\begin{array}{c}\text { A autoridade policial efetuava um resumo dos } \\
\text { fatos através do TCO - Termo Circunstanciado de } \\
\text { Ocorrência. }\end{array}$ & $\begin{array}{c}\text { Prevê um capítulo específico para o atendimento, } \\
\text { pela autoridade policial, para os casos de violên- } \\
\text { cia doméstica contra a mulher. }\end{array}$ \\
\hline A mulher podia desistir da denúncia na delegacia. & A mulher somente poderá renunciar perante o Juiz. \\
\hline $\begin{array}{l}\text { Essa Lei não utilizava a prisão em flagrante do } \\
\text { agressor nem previa a prisão preventiva para os } \\
\text { crimes de violência doméstica. }\end{array}$ & $\begin{array}{l}\text { Possibilita a prisão em flagrante, altera o código de } \\
\text { processo penal, para possibilitar, ao Juiz, a decre- } \\
\text { tação da prisão preventiva, quando houver risco à } \\
\text { integridade física ou psicológica da mulher. }\end{array}$ \\
\hline $\begin{array}{l}\text { A mulher vítima de violência não era informada } \\
\text { quanto ao andamento dos atos processuais. }\end{array}$ & $\begin{array}{l}\text { A mulher, vítima de violência, será notificada } \\
\text { dos atos processuais, especialmente quanto ao } \\
\text { ingresso e saída da prisão do agressor. }\end{array}$ \\
\hline
\end{tabular}

10 Disponível em: http://www.tjrj.jus.br/documents/10136/1607514/cartilha-lei-maria-penha.pdf. Acesso em: 22 abr. 2014. 


\begin{tabular}{|c|c|}
\hline LEI no 9.099/1995 & LEI No 11.340/2006 \\
\hline $\begin{array}{c}\text { A mulher vitima de violência, em geral, não ia } \\
\text { acompanhada de advogado ou defensor público } \\
\text { nas audiências. }\end{array}$ & $\begin{array}{c}\text { A mulher deverá estar acompanhada de advoga- } \\
\text { do ou defensor, em todos os atos processuais. }\end{array}$ \\
\hline $\begin{array}{c}\text { A violência doméstica contra a mulher não era } \\
\text { considerada agravante de pena. }\end{array}$ & $\begin{array}{c}\text { Altera o artigo 61, do Código Penal, para consi- } \\
\text { derar esse tipo de violência como agravante de } \\
\text { pena. }\end{array}$ \\
\hline $\begin{array}{c}\text { A pena para o crime de violência doméstica era } \\
\text { de seis meses a um ano. }\end{array}$ & $\begin{array}{c}\text { A pena do crime de violência doméstica passou } \\
\text { de três meses a três anos. }\end{array}$ \\
\hline $\begin{array}{c}\text { A violência doméstica contra mulher portadora } \\
\text { de deficiência não aumentava a pena. }\end{array}$ & $\begin{array}{c}\text { Se a violência doméstica for cometida contra } \\
\text { mulher portadora de deficiência, a pena será } \\
\text { aumentada em 1/3. }\end{array}$ \\
\hline $\begin{array}{c}\text { Não previa o comparecimento do agressor a pro- } \\
\text { gramas de recuperação e reeducação. }\end{array}$ & $\begin{array}{c}\text { Altera a Lei de Execuções Penais, para permitir } \\
\text { túrio do agressor a programas de recuperação e } \\
\text { reeducação. }\end{array}$ \\
\hline
\end{tabular}

Fonte: Dados da pesquisa.

\section{VIOLÊNCIA DE GÊNERO NO BRASIL APÓS A PROMULGAÇÃO DA LEI MARIA DA PENHA}

Contudo, mesmo com todo o aparato da LMP, a dignidade humana ${ }^{11}$ das mulheres continua sendo ferida, pois elas seguem excluídas, discriminadas no mercado de trabalho e sofrendo inúmeras formas de violência. Situações, essas, que as impedem de conquistarem pleno reconhecimento social; seus direitos de cidadãs não são plenamente exercidos e respeitados ${ }^{12}$.

11 Dignidade humana é "a qualidade intrínseca e distintiva de cada ser humano que o faz merecedor do mesmo respeito e consideração por parte do Estado e da comunidade, implicando, neste sentido, um complexo de direitos e deveres fundamentais que assegurem a pessoa tanto contra todo e qualquer ato de cunho degradante e desumano, como venham a lhe garantir as condições existenciais mínimas para uma vida saudável, além de propiciar e promover sua participação ativa e corresponsável nos destinos da própria existência e da vida em comunhão com os demais seres humanos” (SARLET, 2001, p. 60). 12 A pesquisa de 8 de março de 2012, "Mulher no Mercado de Trabalho: perguntas e respostas", feita com base em dados da Pesquisa Mensal do Emprego de 2009, do Instituto Brasileiro de Geografia e Estatística (IBGE), mostra que as mulheres continuam a ganhar menos que os homens, apesar de terem mais escolaridade. Para que o salário das mulheres se iguale ao dos homens, o rendimento das trabalhadoras precisa subir $38,3 \%$. Outro dado da pesquisa demonstra mais um caso de exclusão das mulheres: em 2009, aproximadamente 35,5\% das mulheres estavam inseridas no mercado de trabalho como empregadas com carteira de trabalho assinada, percentual inferior ao observado na distribuição masculina, que foi de $43,9 \%$. 
A ministra Eliana Calmon, primeira mulher a compor o Superior Tribunal de Justiça, uma das mais altas cortes do Brasil, na palestra de abertura do // Fórum Nacional de Juízes de Violência Doméstica e Familiar contra a Mulher ${ }^{13}$, em 2011 (na época ela ocupava o cargo de Corregedora Nacional de Justiça), chamou a atenção para a necessidade de se propiciarem mais espaços para debate e esclarecimentos em relação à LMP, não apenas nas comunidades, mas também dentro do próprio Judiciário, pois, "lamentavelmente, não temos selecionado bem os magistrados que estão à frente desses juizados”. Entendia ela que os tribunais tratavam o assunto como "uma coisa menor", quando, na realidade, a violência doméstica envolve relações humanas, o que exige maior preparo do magistrado.

Ela citou como exemplo o caso de Eliza Samudio, namorada de Bruno, ex-goleiro do Flamengo, um dos maiores e mais famosos times de futebol do país, que acabou sendo assassinada. Elisa pediu proteção diversas vezes e a juíza do caso negou. A ministra comentou, ainda, o caso do juiz, que, ao julgar uma causa, envolvendo a aplicação da LMP, atacou a mulher, responsabilizando-a por todos os males do mundo, o que classificou como "estarrecedor".

Situações como essas demonstram que há muito a ser feito, pois muitas mulheres ainda morrem, mesmo estando sob medida protetiva, a discriminação em relação à mulher ocorre em todos os níveis de escolaridade ${ }^{14}$ e classe social, como demonstrou Eliana Calmon.

O Estado brasileiro, ao reconhecer a sua responsabilidade em prevenir, punir e erradicar a violência contra a mulher, por meio da LMP e da CF, criou um acordo federativo entre o governo federal, os governos dos estados e dos municípios, para o planejamento de ações que visem à consolidação do Pacto Nacional de Enfrentamento à Violência contra essas Mulheres ${ }^{15}$, por meio da implementação de políticas públicas integradas, em todo território nacional. Dentre as inúmeras ações do Pacto Nacional, encontram-se a capacitação dos aplicadores do direito, agentes da segurança pública e da rede de atendimento à mulher, para garantir a correta e efetiva aplicação da LMP.

A rede de atendimento faz referência a um conjunto de ações e serviços relativos à assistência social, à justiça, à segurança pública e à saúde, que visam à ampliação e à melhoria da qualidade do atendimento. Refere-se, ainda, à identificação e ao encaminhamento adequado das mulheres em situação de violência, bem como à integralidade e humanização do atendimento. Está vinculada à SPM, a partir do Decreto $n^{0} 7.765$, de 25 de junho de 2012, que, em seu artigo 7º, prevê as competências da Secreta-

13 Disponível em: http://www.cnj.jus.br/component/content/article/96-noticias/10344-varas-de-violencia-contra-a-mulher-sofrem-com-falta-de-estrutura-diz-juiza. Acesso em: 19 nov. 2012.

14 Conforme notícia da SPM do dia 24 de abril de 2014, o levantamento feito pelo serviço Disque 180, as vítimas pertencem a todas as faixas de escolaridade, com predominância do ensino fundamental (em 31\%), e médio (em 29\%); $9 \%$ no ensino universitário e 1\% analfabeta. Disponível em: http://mulheres.gov.br/noticias/ultimas_noticias/2014/04/24-04-ligue-180-agora-e-disque-balanco-anual-mostra-que-subiu-para-70-percentual-de-municipios-atendidos. Acesso em: 25 abr. 2014.

15 “O Pacto Nacional pelo Enfrentamento à Violência Contra a Mulher foi lançado em agosto de 2007 pelo Presidente Luiz Inácio Lula da Silva, como parte da Agenda Social do Governo Federal e consiste num acordo federativo entre o governo federal, os governos dos estados e dos municípios brasileiros para o planejamento de ações que visem à consolidação da Política Nacional de Enfrentamento à Violência contra as Mulheres, por meio da implementação de políticas públicas integradas em todo território nacional". Disponível em: http://www.spm.gov.br/subsecretaria-de-enfrentamento-a-violencia-contra-as-mulheres/pacto/Pacto\%20Nacional/view. Acesso em: 3 abr. 2014. 
ria de Enfrentamento à Violência contra as Mulheres $^{16}$, reúne ações e serviços de diversos setores que buscam ampliar e melhorar a qualidade do atendimento às mulheres em situação de violência.

Com a criação da SPM, a rede de atendimento às mulheres em situação de violência foi ampliada. Passou-se a ter outros serviços que não somente as casas, os abrigos e as Delegacias Especializadas de Atendimento à Mulher (DEAM), mas, também, os Centros de Referência da Mulher, as Defensorias da Mulher, as Promotorias da Mulher ou núcleos de gênero nos Ministérios Públicos, os Juizados Especializados de Violência Doméstica e Familiar contra a Mulher, a Central de Atendimento à Mulher (Ligue 180), entre outros.

No quadro abaixo, descrevemos alguns desses serviços, conforme a publicação da Rede de Enfrentamento à Violência contra as Mulheres, da SPM.

Quadro 2 - Serviços de atendimento às mulheres em situação de violência

\begin{tabular}{|c|c|c|}
\hline $\begin{array}{c}\text { Central de Atendi- } \\
\text { mento à Mulher - } \\
\text { Ligue 180 }\end{array}$ & $\begin{array}{c}\text { Criada em } 2005 \text { pela SPM. É um número que pode ser acessado gratuitamen- } \\
\text { te por mulheres de todo o país, com o objetivo de orientá-las em situação de } \\
\text { violência sobre os seus direitos e os serviços disponíveis para o atendimento } \\
\text { de suas demandas; também é responsável por ouvir a sociedade a respeito do } \\
\text { atendimento recebido em cada serviço que integra a Rede. }\end{array}$ \\
\hline $\begin{array}{c}\text { Centros de Atendi- } \\
\text { mento à Mulher em } \\
\text { Situação de Violência }\end{array}$ & $\begin{array}{r}\text { Fazem acolhimento, acompanhamento psicológico e social e prestam orien- } \\
\text { tação jurídica às mulheres em situação de violência., }\end{array}$ \\
\hline $\begin{array}{c}\text { Núcleos de Atendi- } \\
\text { mento à Mulher }\end{array}$ & $\begin{array}{c}\text { Prestam acolhida, apoio psicossocial, e orientação jurídica às mulheres em } \\
\text { situação de violência. Diferenciam-se dos centros de referência de atendi- } \\
\text { mento à mulher pela sua estrutura física e localização - em geral, funcionam } \\
\text { em espaços menores que os Centros de Referência de Atendimento à Mulher } \\
\text { e em municípios de menor porte. }\end{array}$ \\
\hline Casas-Abrigo & $\begin{array}{c}\text { São locais seguros, que oferecem moradia protegida e atendimento integral } \\
\text { a mulheres em risco de vida iminente em razão da violência doméstica. É um } \\
\text { serviço de caráter sigiloso e temporário, no qual as usuárias permanecem por } \\
\text { um período determinado, durante o qual deverão reunir condições necessá- } \\
\text { rias para retomar o curso de suas vidas. }\end{array}$ \\
\hline
\end{tabular}

16 "Art. 70: À Secretaria de Enfrentamento à Violência contra as Mulheres, compete: I — formular políticas de enfrentamento à violência contra as mulheres, que visem à prevenção, combate à violência, assistência e garantia de direitos às mulheres em situação de violência; II - desenvolver, implementar e apoiar programas e projetos voltados ao enfrentamento à violência contra as mulheres, diretamente ou em parceria com organismos governamentais de diferentes entes da federação ou organizações não governamentais; e III — planejar, coordenar e avaliar as atividades da central de atendimento à mulher". Disponível em: http:// www.spm.gov.br/sobre/estrutura/subsecretaria-de-enfrentamento-a-violencia-contra-asmulheres. Acesso em: 2 jun. 2013. 


\begin{tabular}{|c|c|}
\hline $\begin{array}{l}\text { Casas de Acolhimen- } \\
\text { to Provisório }\end{array}$ & $\begin{array}{c}\text { Constituem serviços de abrigo temporário de curta duração (até } 15 \text { dias), } \\
\text { não sigilosos, para mulheres em situação de violência, acompanhadas ou } \\
\text { não de seus filhos, que não correm risco iminente de morte. Vale destacar } \\
\text { que as Casas de Acolhimento Provisório não se restringem ao atendimento } \\
\text { de mulheres em situação de violência doméstica e familiar, devendo acolher } \\
\text { também mulheres que sofrem outros tipos de violência, em especial vítimas } \\
\text { do tráfico de mulheres. }\end{array}$ \\
\hline $\begin{array}{l}\text { Delegacias Especiali- } \\
\text { zadas de Atendimen- } \\
\text { to à Mulher (DEAMs) }\end{array}$ & $\begin{array}{l}\text { São unidades especializadas da Polícia Civil para atendimento às mulheres } \\
\text { em situação de violência. As atividades das DEAMs têm caráter preventivo e } \\
\text { repressivo, devendo realizar ações de prevenção, apuração, investigação, e } \\
\text { enquadramento legal. }\end{array}$ \\
\hline $\begin{array}{l}\text { Defensorias da } \\
\text { Mulher }\end{array}$ & $\begin{array}{c}\text { Têm a finalidade de dar assistência jurídica, orientar, e encaminhar as } \\
\text { mulheres em situação de violência. É um órgão do Estado, responsável pela } \\
\text { defesa das cidadãs que não possuem condições econômicas de ter advogado } \\
\text { contratado por seus próprios meios. }\end{array}$ \\
\hline $\begin{array}{l}\text { Juizados de Violência } \\
\text { Doméstica e Familiar } \\
\text { contra a Mulher }\end{array}$ & $\begin{array}{c}\text { São órgãos da Justiça Ordinária, de competência cível e criminal, que } \\
\text { poderão ser criados pela União (no Distrito Federal e nos Territórios) e pelos } \\
\text { Estados para o processo, julgamento e a execução das causas decorrentes da } \\
\text { prática de violência doméstica e familiar contra a mulher. }\end{array}$ \\
\hline $\begin{array}{l}\text { Centros de Referência } \\
\text { da Assistência Social } \\
\text { (CRAS) }\end{array}$ & $\begin{array}{l}\text { são unidades públicas estatais responsáveis pela organização e oferta de } \\
\text { serviços de proteção social básica do Sistema Único de Assistência Social } \\
\text { enquanto o PAIF (Serviço de Proteção e Atendimento Integral à Família) cons- } \\
\text { titui o principal serviço desenvolvido nos CRAS,, e consiste no trabalho social } \\
\text { com famílias, de caráter continuado, com a finalidade de fortalecer a função } \\
\text { protetiva das famílias, prevenir a ruptura dos seus vínculos, promover acesso } \\
\text { e usufruto de direitos e contribuir na melhoria de sua qualidade de vida. }\end{array}$ \\
\hline $\begin{array}{l}\text { Centros de Referên- } \\
\text { cia Especializados } \\
\text { em Assistência Social } \\
\text { (CREAS) }\end{array}$ & $\begin{array}{c}\text { Ofertam o PAEFI (Serviço de Proteção e Atendimento Especializado a Famí- } \\
\text { lias e Indivíduos), responsável pelo apoio, orientação e acompanhamento } \\
\text { a famílias com um ou mais de seus membros em situação de ameaça ou } \\
\text { violação de direitos. }\end{array}$ \\
\hline
\end{tabular}

Fonte: Dados da pesquisa.

Todos esses serviços são essenciais no auxílio à mulher em situação de violência, mas dados da SPM, demonstram que há a necessidade de expandi-los, pois ainda é muito pequeno o número de municípios que contam com esses serviços. Por exemplo: das 375 delegacias especializadas em todo o Brasil, o que já demonstra ser um número insuficiente para o tamanho do país, um terço delas (125) 
encontram-se no Estado de São Paulo. Precisamos, também, de uma maior divulgação desses serviços, pois, além de serem escassos, são desconhecidos por grande parte da população ${ }^{17}$.

Verifica-se, diante do exposto, a importância da promulgação da LMP para a garantia do direito das mulheres brasileiras a uma vida livre de violência. Tal importância se deve inclusive à participação dos movimentos feministas brasileiros no caso Maria da Penha, levando-o à OEA e gerando a punição ao Estado brasileiro que ocasionou a criação da lei. Há muitas inovações, contudo, que ainda constam apenas no papel.

É preciso, para a efetiva aplicação da LMP a criação e manutenção de todos os mecanismos da rede, tais como juizados, casas-abrigo e centros de referência. É necessário, portanto, para que o Brasil possa efetivamente avançar no combate à violência de gênero e reduzir índices de ameaças, lesões corporais e homicídios contra as mulheres, a efetiva implementação de uma legislação tão inovadora, num Estado ainda muito carente de recursos e capacitação.

\section{REFERÊNCIAS}

BOURDIEU, Pierre. A dominação masculina. Rio de Janeiro: Bertrand Brasil, 2003.

BRASIL. Constituição da República Federativa do Brasil de 1988, [em linha] disponível em: http:// www.planalto.gov.br/ccivil_03/constituicao/constituicao.htm Acesso em: 30 ago. 2014.

BRASIL. Lei n0 9.099, de 26 de setembro de 1995 [em linha]. Disponível em http://www.planalto. gov.br/ccivil_03/leis/l9099.htm. Acesso em: 30 ago. 2014.

BRASIL. Lei no 11.340, de 7 de agosto de 2006, [em linha]. Disponível em: https://www.planalto. gov.br/ccivil_03/_Ato2004-2006/2006/Lei/L11340.htm. Acesso em: 30 ago. 2014.

CAMPOS, Carmen. Da violência real à institucional, do direito penal clássico ao moderno. Cadernos Themis Gênero e Direito, v. 1, n. 1, p. 35-36, 2000.

CUNHA, Aline. Racismo. In: STRECK, Danilo R. et al. (Org.). Dicionário Paulo Freire. Belo Horizonte: Autêntica Editora, 2008. p. 345-347.

FARAH, Maria Ferreira Santos. Gênero e políticas públicas. Estudos Feministas, v. 12, n. 1, p. 47-71, 2004.

FORMIGA, Nilton S. et al. Inventário de sexismo ambivalente: sua adaptação e relação com o gênero.

Psicologia em estudo, v. 7, n. 1, p. 103-111, 2002.

GARCIA, Carla Cristina. Breve história do feminismo. São Paulo: Claridade, 2011.

17 Disponível em: http://www.senado.gov.br/atividade/materia/getPDF.asp?t=130748\&tp=1. Acesso em: 22 jun. 2014. 
GUIMARÃES, Antônio S. Alfredo. Racismo e anti-racismo no Brasil. São Paulo: Edições 34, 1999.

IBGE - Instituto Brasileiro de Geografia e Estatística. Mulher no mercado de trabalho: perguntas e respostas. 2010 [em linha]. Disponível em: http://www.ibge.gov.br/home/estatistica/indicadores/ trabalhoerendimento/pme_nova/Mulher_Mercado_Trabalho_Perg_Resp.pdf. Acesso em: 30 ago. 2014.

MARX, Karl. 0 capital: crítica da economia política. São Paulo: Abril Cultural, 1983.

OEA - Organização dos Estados Americanos. Convenção interamericana para prevenir, punir e erradicar a violência contra a mulher, [em linha]. Disponível em: http://www.cidh.org/Basicos/ Portugues/m.Belem.do.Para.htm [consultado em 30 ago. 2014], 1994.

ONU - Organização das Nações Unidas. Declaração e programa de ação de Viena, [em linha]. Disponível em: http://www.oas.org/dil/port/1993\%20Declara\%C3\%A7\%C3\%A30\%20e\%20 Programa\%20de\%20Ac\%C3\%A7\%C3\%A30\%20adoptado\%20pela\%20Confer\%C3\%AAncia\%20 Mundial\%20de\%20Viena\%20sobre\%20Direitos\%20Humanos\%20em\%20junho\%20de\%201993. pdf. Acesso em: 30 ago. 2014.

PESTANA, Yasmin Oliveira Mercadante. Fui agredida: dou início ou não ao processo? 2010 [em linha]. Disponível em: http://www.defensoria.sp.gov.br/dpesp/Repositorio/41/Documentos/ artigo\%20ibccrim\%20pronto_revisado.pdf. Acesso em: 30 ago. 2014.

PINHEIRO, Jair. Novos movimentos sociais classistas. Aurora, ano 4, n. 6, p. 109-114, 2010.

PINTO, Céli Regina Jardim. Uma história do feminismo no Brasil. São Paulo: Perseu Abramo, 2003.

PINTO, Céli Regina Jardim. Feminismo, história e poder. Revista de Sociologia e Política, v. 18, n. 36, p. 15-23, 2010.

SARLET, Ingo Wolfgang. Dignidade da pessoa humana e direitos fundamentais na Constituição

Federal de 1988. Porto Alegre: Livraria do Advogado, 2001. 
1 Mestra em Memória Social e Bens Culturais pela UNILASALLE; Especialista em Direito do Consumidor pela Universidade Federal do Rio Grande do Sul; Graduada em Direito pela Pontifícia Universidade Católica do Rio Grande do Sul. E-mail: kellenvl@hotmail.com

2 mestra em Direito e doutora em Ciências Humanas (área de concentração Estudos de Gênero), com período de estágio sanduíche no Institut National d'Études Demographiques, com o Prof. Michel Bozon; Graduada em Ciências Jurídicas e Sociais; Professora e pesquisadora do Projeto de Mestrado em Direito e Sociedade do Unilasalle/Canoas e professora da Uniritter. E-mail: paulapinhal@hotmail.com

3 Mestra em Psicologia Social e da Personalidade, Doutora em Psicologia com período de estágio sanduíche na Escola de Altos Estudos em Ciências Sociais, com a Profa. Denise Jodelet; Especialista em Gestão Social; Psicóloga; Professora e pesquisadora no Pós-Graduação em Memória Social e Bens Culturais do Unilasalle/Canoas; Líder do Grupo de Pesquisa "Mariposas: gênero, sexualidades e feminismos". E-mail: alineaccorssi@gmail.com

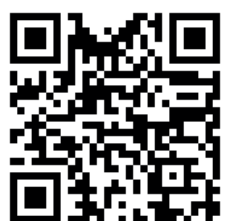

A autenticidade desse artigo pode ser conferida no site https://periodicos. set.edu.br

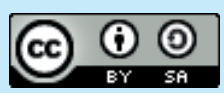

Este artigo é licenciado na modalidade acesso abertosob a Atribuição-Compartilhalgual CC BY-SA
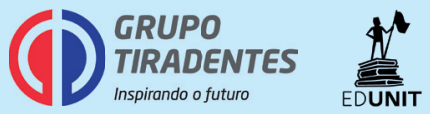